\title{
MỘT SỐ GIẢI PHÁP NÂNG CAO HIỆ QUẢ GIẢNG DẠY CÁC MÔN LÝ LUẬN CHÍNH TRI Ở TRƯỜnG ĐẠI HỌC CÔNG NGHIỆP THÀNH PHỐ HỒ CHÍ MINH
}

\author{
BÙI THI HẢO \\ Trường Đại học Công nghiệp Thành phố Hồ Chí Minh \\ haosaigon74@gmail.com
}

Tóm tắt. Từ thực tiễn giảng dạy tại Trường Đại học Công nghiệp thành phố Hồ Chí Minh, tác giả phân tích thực trạng, đề xuất giải pháp phù hợp nhằm nâng cao hiệu quả giảng dạy các môn Lý luận Chính trị, góp phần thực hiện cam kết với người học, với xã hội về chất lượng, uy tín của Nhà trường trong giai đoạn hiện nay.

Từ khoá. Lý luận chính trị; Phương pháp dạy học Lý luận Chính trị

\section{SOME SOLUTIONS TO ENHANCE EFFECTIVENESS IN TEACHING POLITICAL THEORIES IN INDUSTRIAL UNIVERSITY OF HO CHI MINH AT CURRENT STAGE}

\begin{abstract}
Basing on teaching experience in Industrial University of Ho Chi Minh, the author has analysed the real situation and proposed some appropriate solutions in order to improve effectiveness of teaching political theories, and implement the commitments to the learners and the society with regards to training quality and the university's prestige in current period.
\end{abstract}

Key words. Political theory, teaching methodology in political theory.

\section{MỞ ĐÀ̀U}

Giáo dục - đào tạo là sự nghiệp của toàn dân, trong đó, những người làm công tác giáo dục phải luôn nêu cao tinh thần trách nhiệm, tự giác, tích cực tham gia vào quá trình đổi mới giáo dục. Chất lượng, hiệu quả giáo dục - đào tạo đại học hiện nay còn thấp so với yêu cầu, mang nặng tính lý thuyết, đào tạo thiếu gắn kết với nghiên cứu khoa học, sản xuất kinh doanh và nhu cầu thị trường lao động, phương pháp giảng dạy, kiểm tra và đánh giá kết quả lạc hậu và thiếu tính thiết thực, nhất là các môn thuộc khối lý thuyết. Do đó, đổi mới phương pháp dạy học cho phù hợp với xu thế của thế giới, đáp ứng yêu cầu của người học phục vụ mục tiêu $\mathrm{CNH}$, $\mathrm{HĐH}$ đất nước là minh chứng cho quan điểm Đổi mới để phát triển, thay đổi để tiến bộ, được sự quan tâm của cả hệ thống chính trị, toàn dân.

Triển khai quan điểm đổi mới trong giáo dục - đào tạo trong bối cảnh trường tự chủ với mục tiêu đến năm 2020 trở thành một trong những trường đại học hàng đầu Việt Nam, trường Đại học Công nghiệp Thành phố Hồ Chí Minh (ĐHCN TP HCM) thực hiện đào tạo theo học chế tín chỉ với triết lý :Tôn trọng người học, xem người học là trung tâm của quá trình đạo tạo. Người học chủ động trong việc tiếp thu kiến thức, sử dụng hiệu quả thời gian, nâng cao khả năng tự học, tự nghiên cứu, phát huy cao độ năng lực, sức sáng tạo.

Trong hệ thống đào tạo đại học, bộ môn Lý luận Chính trị (LLCT) được giảng dạy trong tất cả các trường với những ngành nghề và hệ đào tạo khác nhau. Bên cạnh nội dung khoa học, bộ môn có vai trò quan trọng trong việc giáo dục đạo đức, lối sống, định hướng lý tưởng cho sinh viên. Thực tế giảng dạy các môn LLCT ở trường ĐHCN TP HCM đạt hiệu quả chưa cao, thiếu định hướng tư tưởng, lối sống cho sinh viên. Chưa tạo được nền tảng vững chắc cho sinh viên trong việc tiếp cận các môn khoa học chuyên ngành... Do đó, nâng cao chất lượng giảng dạy các môn LLCT tại trường ĐHCN TP HCM sẽ góp phần thể hiện rõ trách nhiệm của nhà trường đối với người học và xã hội, khẳng định được uy tín của trường, đáp ứng nguồn nhân lực phục vụ khi nền kinh tế thị trường, hội nhập quốc tế. 


\section{NỌI DUNG}

\section{Thực trạng dạy và học các môn Lý luận Chính trị tại trường Đại học Công nghiệp Thành phố Hồ Chí Minh}

Về đội ngũ cán bộ, giảng viên trong khoa: Hiện tại, Khoa Lý luận Chính trị có 28 cán bộ, giảng viên cơ hữu, trong đó có 05 tiến sỹ, 21 thạc sỹ (trong đó có $02 \mathrm{NCS}$ ), 02 cử nhân và đảm nhận 03 môn học chính cho hệ đại học, cao đẳng là Những nguyên lý cơ bản của chủ nghĩa Mac - Lênin (05 tín chỉ); Đường lối Cách mạng của Đảng Cộng sản Việt Nam (03 tín chỉ); Tư tưởng Hồ Chí Minh (02 tín chỉ). Giảng viên khoa đều đạt chuẩn dạy đại học, tinh thần trách nhiệm cao. Từ năm 2015 đến nay, giảng viên trong khoa giảng dạy đều trên chục ngàn tiết, vượt mức gần $30 \% /$ năm. Tuy nhiên, do khối lượng công việc lớn, lớp đông sinh viên nên giảng viên gần như xoay vòng trong công tác giảng dạy, kiểm tra, đánh giá, ảnh hưởng không nhỏ đến công tác đổi mới phương pháp giảng dạy và nghiên cứu khoa học.

Về công tác kiểm tra, đánh giá: Khoa LLCT xây dựng bộ ngân hàng đề thi theo hình thức trắc nghiệm khách quan để tiến hành công tác kiểm tra, đánh giá đối với tất cả các môn học. Tiêu chí xây dựng là 15 câu hỏi trắc nghiệm khách quan/tiết học và có các mức câu hỏi từ dễ đến khó để đánh giá chính xác năng lực sinh viên. Bộ ngân hàng câu hỏi được phòng Khảo thí và đảm bảo chất lượng lưu giữ, chịu trách nhiệm quản lý, xuất đề thi và chấm trên máy. Toàn bộ Bộ ngân hàng câu hỏi thi trác nghiệm khách quan này được dùng để đánh giá thi giữa kì, còn thi cuối kì thì Khoa LLCT xây dựng bộ ngân hàng câu hỏi thi tự luận với 3 chuẩn đầu ra từ dễ đến khó và thực hiện chấm chéo. Như vậy, công tác kiểm tra, đánh giá thi cử khách quan, không phụ thuộc vào bất kỳ một giáo viên cụ thể nào. Hàng năm giảng viên bộ môn đều được yêu cầu chỉnh sửa, bổ sung, hoàn thiện câu hỏi cho phù hợp với điều kiện chính trị - xã hội và thực tiễ்n phát triển của đất nước. Mặc dù vậy, thực tế vẫn còn có câu hỏi trắc nghiệm, tự luận chưa bám sát thực tiễn, hỏi ở mức độ đòi hỏi sinh viên chỉ cần nhớ, thuộc lòng... nên chưa phát huy hết tính chủ động, sáng tạo, hiểu biết của sinh viên.

Về kết quả học tập của sinh viên: Đối tượng giảng dạy của bộ môn LLCT là sinh viên năm thứ nhất, thứ hai. Với sinh viên năm thứ nhất, các em đang quen với phương pháp học ở trung học phổ thông nên khi tiếp cận với môn học mà các em cho là khá "trừu tượng" còn nhiều khó khăn.

Tỷ lệ sinh viên đạt các môn Lý luận Chính trị học kì II, năm học 2017 - 2018

\begin{tabular}{|c|c|c|c|c|c|}
\hline STT & Môn học & $\begin{array}{c}\text { Số sinh viên } \\
\text { dự thi }\end{array}$ & $\begin{array}{c}\text { Só́ sinh } \\
\text { viên đạt }\end{array}$ & $\begin{array}{c}\text { Só́ sinh viên } \\
\text { không đạt }\end{array}$ & Tỷ lệ đạt \\
\hline 1 & $\begin{array}{c}\text { Những nguyên lý cơ bản của Chủ } \\
\text { nghĩa Mác - Lênin }\end{array}$ & 1.225 & 1.040 & 285 & $84 \%$ \\
\hline 2 & Tư tưởng Hồ Chí Minh & 4.038 & 3.706 & 332 & $91 \%$ \\
\hline 3 & $\begin{array}{c}\text { Đường lối cách mạng của Đảng } \\
\text { Cộng sản Việt Nam }\end{array}$ & 5.482 & 4.742 & 740 & $86 \%$ \\
\hline & Tổng cộng: & 10.745 & 9.488 & 1.357 & $86 \%$ \\
\hline
\end{tabular}

Nguồn: Khoa Lý luận Chính trị

Nếu nhìn vào kết quả thống kê thì tỷ lệ sinh viên đạt vượt qua các môn LLCT của học kì II năm học 2017 - 2018 khá cao, trên $86 \%$, tuy nhiên đi sâu vào cụ thể thì tỷ lệ đạt chuẩn đầu ra của môn học khồng cao và chủ yếu sinh viên đạt ở các chuẩn 1 , chuẩn 2 (chuẩn trình bày, giải thích) còn chuẩn 3 (phân tích) thì số sinh viên đạt thấp. Cụ thể, ở chuẩn 3 môn Tư tưởng Hồ Chí Minh ở học kì II năm học 2017 - 2018, số lượng sinh viên đạt chỉ $40 \%$. Điều đó cho thấy sinh viên mới chỉ dừng lại ở việc học và vượt qua các môn học này ở mức độ biết và hiểu còn mức độ phân tích nhận thức các vấn đề thực tiễn chính trị - xã hội thì rất lúng túng. Bài học từ sự kiện Thiên An Môn đã được Đặng Tiểu Bình tổng kết: Sai lầm lớn nhất của muoòi năm cải cách là sụ bất lực của việc giáo dục tư tưởng chính trị, không giáo dục tốt thanh niên và đông đảo cán bộ Đảng viên, do đó, chỉ cần một vài sự kích động tả khuynh thì lập tức xảy ra bạo động, bạo loạn.

Theo khảo sát của tác giả đối với sinh viên học kỳ III (học kì hè), năm học 2017 - 2018 (môn Tư tưởng Hồ Chí Minh và môn Đường lối Cách mạng của Đảng Cộng sản Việt Nam) đa số sinh viên đều trả lời 
rằng: Bộ môn Lý luận Chính trị có giá trị lý luận và thực tiễn cao nhưng khó học. Không có sinh viên nào "rất thích" học những môn này, chỉ có một số rất ít (dưới 5\%) "thích" học nhưng lý do là vì dễ đạt điểm cao. Đa số sinh viên nghĩ là bộ môn này khó, lý thuyết. Quan điểm của sinh viên là do bắt buộc phải học nên họ học đối phó cho qua. Như vậy, mặc dù sinh viên vượt qua những môn học này nhưng công tác giáo dục, nhất là giáo dục chính trị tư tưởng, đạo đức, lối sống, niềm tin, lý tưởng cho sinh viên đang là khoảng trống, do đó, vấn đề đặt ra là phải có giải pháp thích hợp để sinh viên không chỉ vượt qua những môn học này mà thông qua môn học giúp sinh viên hình thành niềm tin, sống có lý tưởng.

Bên cạnh đó, việc chuyển đổi từ học chể niên chế sang học chế tín chỉ đối với các môn LLCT giảm về số tiết nhưng không giảm nhiều nội dung gây áp lực không nhỏ đối với giảng viên. Trong thực tiễn, nhiều giảng viên lo chạy đua với truyền thụ kiến thức và áp lực của tiến độ giảng dạy nên chỉ sử dụng các phương pháp dạy học truyền thống như thuyết trình, diễn giải mà chưa quan tâm đến áp dụng các phương pháp mới.

Công tác định hướng nghề nghiệp, giáo dục đạo đức, lối sống, lý tưởng, rèn luyện kỹ năng cho sinh viên chưa được thực hiện nghiêm túc. Một số giảng viên còn sa đà vào phân tích các tệ nạn của xã hội gây phản tác dụng, sai lệch với mục tiêu giáo dục, định hướng. Bên cạnh đó, tâm lý sinh viên năm nhất còn đang "thả lỏng" với thành quả mới kết thúc 12 năm miệt mài học tập; cuộc sống xa nhà, phải tự lập do đó có nhiều khó khăn cộng với sự tác động của nền kinh tế thị trường và lối sống thực dụng của một bộ phận sinh viên nên tác động không nhỏ đến việc học tập các môn LLCT. Tình trạng sinh viên thụ động, không thích ứng kịp với phương thức đào tạo mới, dựa vào giảng viên, chưa quen làm việc nhóm; tình trạng coi trọng lĩnh hội tri thức hàn lâm hơn rèn luyện kỹ năng nghiệp vụ khá phổ biến; việc xây dựng kế hoạch học tập cho bản thân hay đăng ký môn học còn thụ động, lúng túng. Sinh viên chưa có thói quen coi những giờ tự học, tự nghiên cứu tài liệu ở nhà là một phần của môn học nên khi giảng dạy những đơn vị kiến thức cần trình bày, trao đổi tại lớp kết quả không cao. Sinh viên không không xác định được động cơ học tập dẫn đến học đối phó, học thuộc kiến thức một cách máy móc, do đó khơi gợi đam mê, hứng thú học tập cho sinh viên là việc làm cấp thiết.

\section{Giải pháp nâng cao hiệu quả giảng dạy các môn Lý luận Chính trị tại trường Đại học Công nghiệp Thành phố Hồ Chí Minh}

Nâng cao hiệu quả giảng dạy nói chung, giảng dạy các môn LLCT nói riêng ở trường ĐHCN TP HCM trong tình hình hiện nay là tất yếu khách quan. Quá trình chỉ đạt hiệu quả khi được tiến hành đồng bộ với đổi mới nội dung, phương pháp dạy học, phương pháp kiểm tra, đánh giá và tăng cường cơ sở vật chất và trang thiết bị dạy học hiện đại, quá trình thực hiện đòi hỏi sự thống nhất và đồng bộ giữa nhà trường, nhà giáo và sinh viên. Do đó, để nâng cao hiệu quả giảng dạy các môn LLCT, cần thực hiện những giải pháp cơ bản sau:

\section{Thứ nhất, trước khi giảng dạy, giảng viên phải làm việc trục tiếp với lớp mình để xác định cách tiếp cận môn học theo hướng trao đổi, thảo luận.}

Như trên đã trình bày, do bộ môn LLCT đã giảm về thời lượng nhưng nội dung chương trình giảm ít, do đó, giảng viên lo chạy đua với việc hoàn thành nội dung và đảm bảo tiến độ nên không thể thực hiện đổi mới phương pháp giảng dạy. Giải pháp cho vấn đề này là giảng viên và sinh viên thống nhất trước với nhau về cách tiếp cận môn học. Giảng viên yêu cầu sinh viên đọc và chuẩn bị nội dung trước khi trao đổi, thảo luận ở trên lớp. Khi đến lớp, giảng viên sẽ nêu vấn đề cho sinh viên trao đổi, thảo luận, giảng viên phải là trọng tài, là người giải thích vướng mắc, chỉ ra nguồn thông tin từ đó hệ thống hoá kiến thức, khái quát hoá các kết luận. Để việc chuẩn bị, tự nghiên cứu đạt kết quả cao, giảng viên cần cung cấp hệ thống học liệu và phương pháp nghiên cứu cho sinh viên. Áp dụng giải pháp này rất thuận lợi đối với các lớp thuộc hệ Tiên Tiến của trường, do mô hình lớp nhỏ, phòng học lý tưởng, có các phương tiện dạy học hỗ trợ, giảng viên có trình độ cao, sinh viên được lựa chọn giáo viên giảng dạy...

Có thể nói, dạy học theo phương pháp sinh viên phải làm việc trước, phải động não rằng mình sẽ học gì, sẽ phải chuẩn bị gì và định hướng trao đổi như thế nào là đảo lộn thứ tự của hoạt động dạy học truyền thống. Tuy nhiên, việc học tập của sinh viên trong trường đại học gắn liền với nghề nghiệp trong tương lai nên phần lớn sinh viên ý thức được tầm quan trọng của việc học để trở thành những chuyên gia trong lĩnh vực được đào tạo. Do đó, nếu giảng viên khơi gợi được sự tích cực, chủ động, tìm tòi, sáng tạo của sinh viên, tạo nên khát vọng mở rộng, đào sâu suy nghĩ trong học tập sẽ đạt kết cao, bởi "con đuờng giáo 
dục là tập tự sủ dụng nhũng khả năng của mình, tụ sử dụng cái đầu của mình” (Kant). Mặt khác, giảng viên phải là người hiểu sâu sắc vấn đề mình giảng dạy và có lượng thông tin, kiến thức rộng để giải đáp thắc mắc của sinh viên. Thực hiện giải pháp này giúp sinh viên thành thạo trong hoạt động nhóm nên công tác giảng dạy sẽ hiệu quả hơn.

Để đạt hiệu quả cao trong quá trình dạy học, giảng viên nên kết hợp các phương pháp trong dạy học đại học như PBL (Problem - Based Learning; Project Based Learning) và các phương pháp truyền thống như thuyết trình, giảng giải. Mỗi phương pháp đều có tính độc lập tương đối và giới hạn của mình, vượt ra ngoài giới hạn đó thì cần bổ sung bằng một phương pháp khác. Do đó, tùy vào nội dung từng bài giảng và từng chuyên ngành mà vận dụng mềm dẻo, linh hoạt các phương pháp truyền thống và hiện đại nên khi vận dụng linh hoạt chúng sẽ bồ sung cho nhau một cách thống nhất tạo ra sức mạnh thuyết phục trong giảng dạy. Tránh trường hợp đề cao quá mức một vài phương pháp mà quay lưng lại với các phương pháp truyền thống khác.

Thực tế, giảng viên khoa LLCT đã thực hiện phương pháp dạy học nêu vấn đề, tuy nhiên, mới chỉ dừng lại ở hình thức mà chưa phát huy được tính tích cực, chủ động trong sinh viên. Do đó, thời gian tới, giảng viên trong khoa nên chú trọng nâng cao trình độ, tích cực học hỏi lẫn nhau, tham gia các lớp tập huấn để nắm vững phương pháp dạy học hiện đại, phù hợp bộ môn.

\section{Thứ hai, nội dung giảng dạy đảm bảo tính khoa học và gắn liền với thục tiễn.}

Học LLCT là học tinh thần, học lập trường, quan điểm của Chủ nghĩa Mác - Lênin để áp dụng giải quyết những vấn đề thực tiễn. Với tỉnh thần đó, giảng dạy các môn LLCT không chỉ truyền đạt những nội dung nguyên lý, quy luật mà còn định hướng tư tưởng chính trị, giải đáp được những vấn đề do thực tiễn đặt ra. Phần lớn sinh viên quen với cách học từ phổ nên khi tiếp cận các môn học mang tính hàn lâm, lý thuyết, sinh viên không hứng thú học tập. Trong giảng dạy, nội dung môn học phải đảm bảo tính khoa học, tuy nhiên, Chính trị như hơi thở hằng ngày của cuộc sống nên bộ môn Lý luận Chính trị nếu chỉ chuyển tải nội dung hàn lâm sẽ khó đảm bảo thực hiện được chức năng giáo dục tư tưởng, định hướng tư tưởng, lý tưởng cho sinh viên. Đối với từng môn cụ thể phải có phương pháp tiếp cận mang tính đặc trưng. Cụ thể, môn Những nguyên lý cơ bản của chủ nghĩa Mác - Lênin cách tiếp cận phải dựa trên hệ tư tưởng chính trị khoa học; môn Đường lối cách mạng của Đảng Cộng sản Việt Nam, cách tiếp cận dựa trên tư tưởng cách mạng giải phóng dân tộc; đối với môn Tư tưởng Hồ Chí Minh thì phải dựa vào quan điểm lịch sử, cụ thể để nhận thức, đánh giá... Điều thuận lợi rất lớn là hiện nay môn giáo dục công dân ở phổ thông trở thành một trong ba môn thuộc tổ hợp Khoa học xã hội thi xét tốt nghiệp và xét tuyển vào đại học, đây là điều kiện thuận lợi vì thông qua việc học ở phổ thông, sinh viên không còn xa lạ với các thuật ngữ, khái niệm và bước đầu nắm bắt các nguyên lý, quy luật, phạm trù... làm nền tảng học chuyên sâu trong giai đoạn học đại học.

Các môn LLCT gắn liền với "hơi thở của cuộc sống" nên giảng dạy các môn LLCT tại trường ĐHCN TP HCM phải bám sát với các sự kiện và sự đổi thay hằng ngày của đất nước sẽ thuyết phục sinh viên đồng hành cùng với dân tộc trong hành trình đổi mới, phát triển và hội nhập. Để làm được điều đó, giảng viên giảng dạy LLCT phải phân tích khúc triết các mâu thuẫn và sự kiện phức tạp trong xã hội, có khả năng chọn tư liệu, nắm vững phương pháp luận Mác xít và tin vào sự thắng lợi tất yếu của cách mạng. Làm được điều này sẽ gây hứng thú học tập cho sinh viên, hiệu quả giảng dạy các môn LLCT sẽ dần được nâng cao.

\section{Thứ ba, phương pháp đánh giá phải phát huy đự̣c khả năng tư duy sáng tạo của sinh viên}

Đánh giá quá trình học tập của sinh viên thông qua các cấp độ tư duy: Biết, hiểu, vận dụng, phân tích, tổng hợ và sáng tạo. Hiện tại, phương pháp kiểm tra, đánh giá sinh viên của bộ môn LLCT là sử dụng bộ ngân hàng câu hỏi theo hình thức trắc nghiệm khách quan phục vụ cho kiểm tra giữa học kì và thi tự luận vào cuối học kì. Bộ ngân hàng câu hỏi trắc nghiệm và tự luận bám sát nội dung chương trình môn học và thực tiễn đổi mới đât nước. Việc kết hợp nhiều phương pháp kiểm tra, đánh giá đảm bảo tính xác thực, đúng đắn trong đánh giá năng lực sinh viên.

Mặc dù bộ ngân hàng câu hỏi trắc nghiệm và tự luận được bổ sung, chỉnh sửa hàng năm nhưng về cơ bản mới chỉ dừng lại ở 2 chuẩn đầu ra là biết và hiểu. Sinh viên chủ yếu mới chỉ dừng lại ở kĩ năng biết, hiểu còn khả năng phân tích nhận thức và giải quyết các vấn đề cính trị - xã hội nảy sinh trong cuộc sống còn bỡ ngỡ. Do đó, trong thời gian tới, khoa LLCT nên củng cố tăng cường những câu hỏi đòi hỏi khả năng nhận thức thực tiễn cao mới phát huy được hứng thú, tính chủ động, sáng tạo học tập của sinh viên. 
Để thực hiện được giải pháp này, giảng viên phải công tâm, nhạy bén với các vấn đề mới trong cuộc sống, đánh giá đúng và bảo vệ được những sáng tạo, nhân tố mới. Giúp sinh viên hình thành thói quen hoài nghi khoa học, lật lại vấn đề, gắn học tập với nghiên cứu khoa học theo phương châm: "mục đích của sự học đại học đại học không phải là học, mà là đánh thức cuộc đời mới trong thanh niên, đánh thức một tinh thần khoa học bất diệt" (The real purpose of a university is not learning, but the awakening of a new life in the youth, of really scientific spirit). Giảng viên phải có lập trường kiên định, tinh thần vượt khó trong học tập, nghiên cứu khoa học. Khoa LLCT nên tổ chức biên soạn Bài giảng làm tài liệu học tập phù hợp với đặc điểm sinh viên, mặt khác, lãnh đạo nhà trường tạo điều kiện cho giảng viên khoa LLCT đi thực tế và tập huấn nhiều hơn để nâng cao kiến thức thực tiễn phục vụ công tác giảng dạy.

\section{KÉT LUẬN}

Giáo dục - đào tạo là một quá trình chịu sự tác động của nhiều yếu tố, tuy nhiên, công tác giảng dạy của người giảng viên đóng vai trò quan trọng, nhất là môn học có tính định hướng giáo dục chính trị tư tưởng, niềm tin, lối sống như bộ môn LLCT. Trên cơ sở luận giải các vấn đề thực tiễn, bài viết đạt được một số kết quả sau:

Một là, chỉ ra tính cấp thiết của việc nâng cao chất lượng giảng dạy các môn LLCT trong bối cảnh hiện nay tại trường ĐHCN TP HCM.

Hai là, phân tích thực trạng đội ngũ giáo viên giảng dạy tại khoa LLCT; thực trạng việc học các môn LLCT của sinh viên trường năm học 2017 - 2018; chỉ ra những ưu điểm, hạn chế của việc kiểm tra, đánh giá kết quả học tập của sinh viên làm cơ sở cho việc đề ra các giải pháp hợp lý trong việc nâng cao chất lượng giảng dạy các môn LLCT tại trường.

Ba là, bài viêt đưa ra một số giải pháp phù hợp với thực trạng dạy học tại trường làm cơ sở cho giảng viên, sinh viên, khoa LLCT và nhà trường tham khảo nhằm nâng cao chất lượng giảng dạy các môn LLCT, góp phần thực hiện cam kết với người học, với xã hội về chất lượng, uy tín của Nhà trường trong giai đoạn hiện nay.

\section{TÀI LIỆU THAM KHẢO}

[1] Chính Phủ (2005), Nghị quyết 14/2005/NQ-CP về Đổi mới cơ bản, toàn diện giáo dục ở Việt Nam, ban hành ngày 02.11.2005.

[2] Bộ Giáo dục - Đào tạo (2007), Quy chế đào tạo đại học, cao đẳng chính quy theo học chế tín chỉ, ban hành kèm theo Quyết định số 43/2007/QĐ-BGDĐT.

[3] Trường ĐHCN TP HCM (2007), Quyết định 235/QĐ-ĐHCN-ĐT về Đào tạo theo hệ thống tín chỉ, ban hành ngày 30.8.2007.

[4] Nguyễn Phan Thu Hằng (2009), Vấn đề cơ bản của đổi mới phương pháp dạy học bậc đại học là dạy cho sinh viên cách tự học, tự nghiên cứu, Kỷ yếu hội thảo Đổi mới phương pháp dạy học năm 2009, Đại học Sài Gòn.

[5] Lê Trọng Đại, Nguyễn Đức Vượng (2009), Tìm lời giải cho bài toán đào tạo theo hệ thống tín chỉ ở trường đại học, Kỷ yếu hội thảo “Đổi mới phương pháp dạy học đại học theo hệ thống tín chỉ”.Đại học Huế.

Ngày nhận bài: 01/03/2018

Ngày chấp nhận đăng:24/02/2018 